\title{
Author Correction: Targeting public neoantigens for cancer immunotherapy
}

Alexander H. Pearlman (1D, Michael S. Hwang, Maximilian F. Konig (D), Emily Han-Chung Hsiue, Jacqueline Douglass, Sarah R. DiNapoli, Brian J. Mog (1), Chetan Bettegowda, Drew M. Pardoll, Sandra B. Gabelli, Nicholas Papadopoulos (i), Kenneth W. Kinzler, Bert Vogelstein and Shibin Zhou (D)

Correction to: Nature Cancer https://doi.org/10.1038/s43018-021-00210-y, published online 17 May 2021.

In the version of this article initially published, the seventh label along the vertical axis of Fig. 3 (IDH1 p.Arg132Cys) was incorrect, and ten labels (TCGA project names) along the horizontal axis of Fig. 3 were not in the correct order. The correct label along the vertical axis is 'KRAS p.Gly12Cys', and the correct order for labels along the horizontal axis is now provided. The errors have been corrected in the HTML and PDF versions of the article. 


\section{Original}

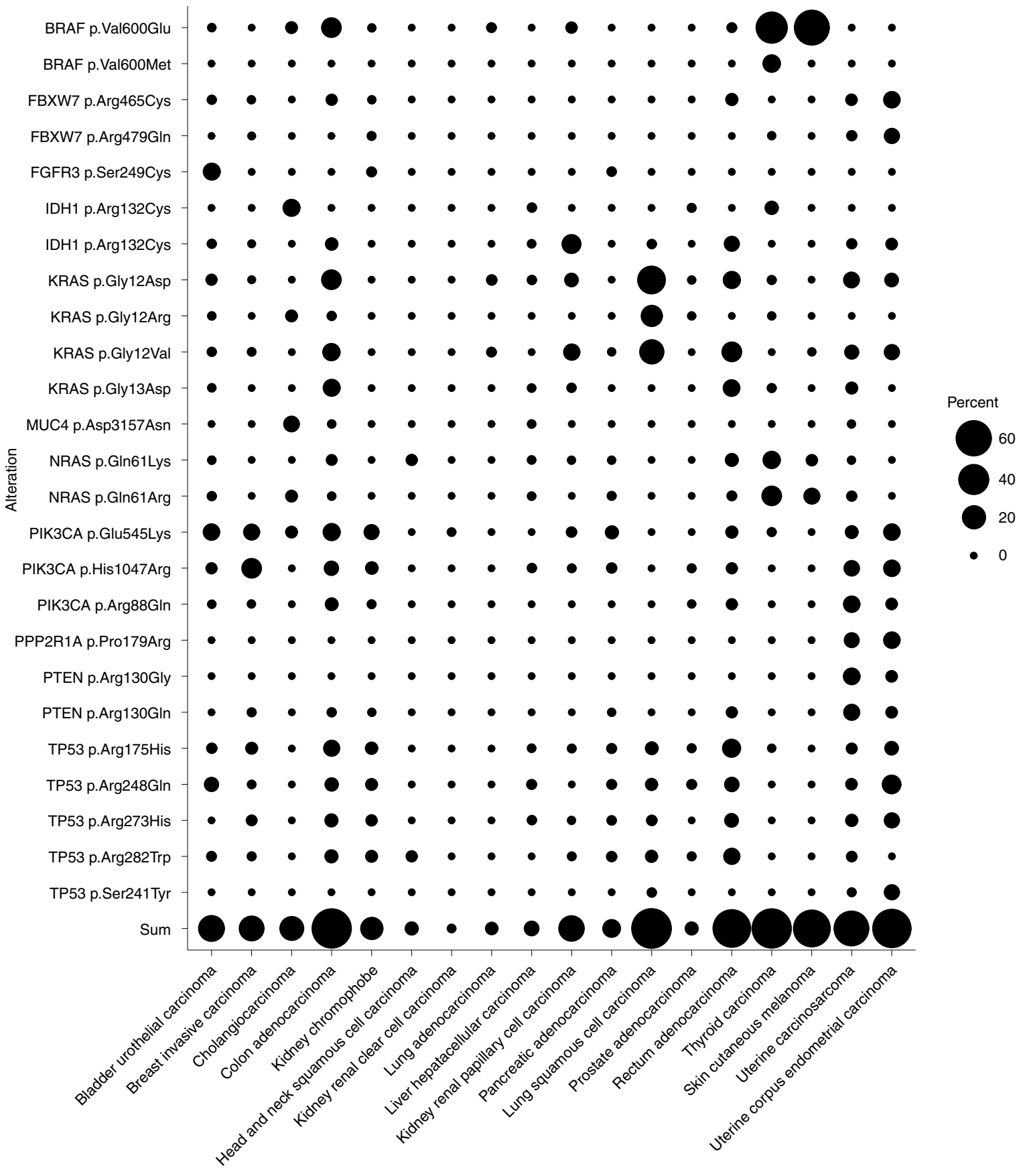

TCGA project 


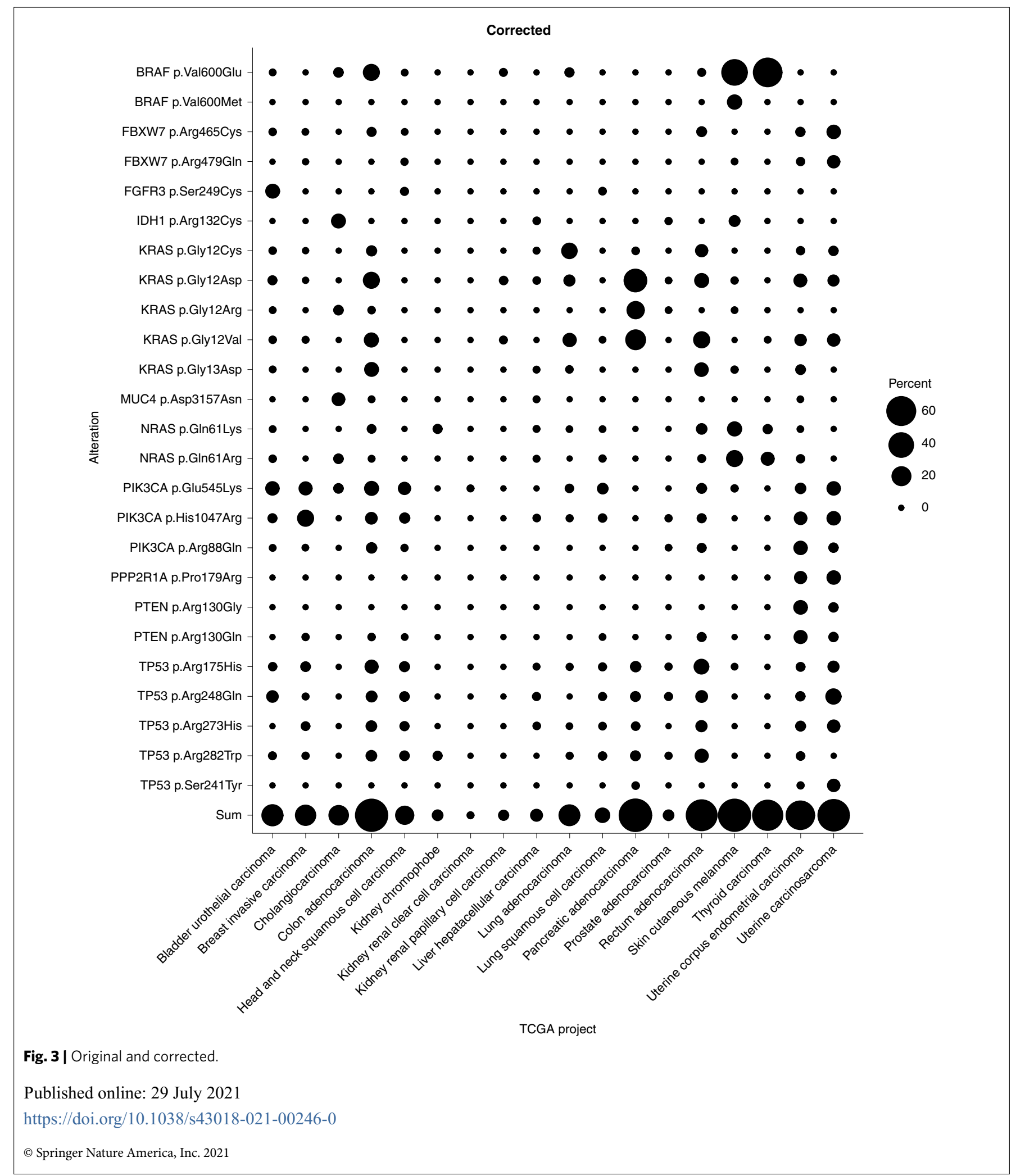

